\title{
Metal Welding Sculptural Portraiture for the Historical Remembrance of Political Figures in Ghana: The Case of Osagyefo Dr. Kwame Nkrumah
}

By Isaac Kwabena Agyei, Owusu Oteng Bediako \& Dickson Adom

Kwame Nkrumah University of Science and Technology

Abstract- Artists in Ghana who produce sculptural busts or portraits mostly limit their production materials to clay, P.O.P., cement, and metal cast. These materials may have defects and could be potentially affected by environmental conditions for lifelong periods. Aluminium welding is not practiced by artists in the fabrication of photorealistic portraits. The techniques used by artists in Ghana is the clay and cement model, which can further be used in the creation of a cast resin or metal. The researchers investigated the most used materials for creating realistic busts. The pros and cons of the materials as well as their techniques were rigorously analyzed in comparison with the aluminium forming and welding technique. Welders are constrained as far as what they can create. Mostly welders produce iron gates, burglar-proof and security locks. There is the need to diversify the technique to be able to produce portraits as a step in experimenting and diversifying the material and technique.

Keywords: portrait; photorealistic; repousse; kwame nkrumah; aluminium.

GJHSS-A Classification: FOR Code: 190499

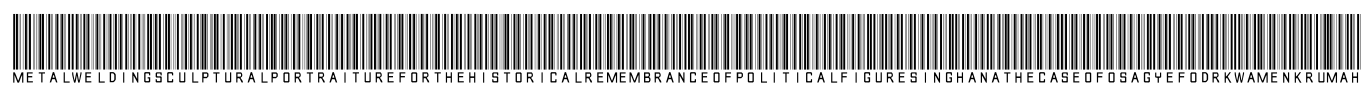

Strictly as per the compliance and regulations of:

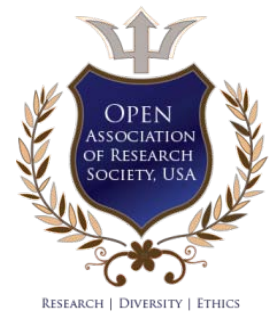

(c) 2020. Isaac Kwabena Agyei, Owusu Oteng Bediako \& Dickson Adom. This is a research/review paper, distributed under the terms of the Creative Commons Attribution-Noncommercial 3.0 Unported License http://creativecommons.org/licenses/by-nc/ 3.0/), permitting all non-commercial use, distribution, and reproduction in any medium, provided the original work is properly cited. 


\title{
Metal Welding Sculptural Portraiture for the Historical Remembrance of Political Figures in Ghana: The Case of Osagyefo Dr. Kwame Nkrumah
}

\author{
Isaac Kwabena Agyei ${ }^{\alpha}$, Owusu Oteng Bediako ${ }^{\circ}$ \& Dickson Adom ${ }^{\circ}$
}

Abstract Artists in Ghana who produce sculptural busts or portraits mostly limit their production materials to clay, P.O.P., cement, and metal cast. These materials may have defects and could be potentially affected by environmental conditions for lifelong periods. Aluminium welding is not practiced by artists in the fabrication of photorealistic portraits. The techniques used by artists in Ghana is the clay and cement model, which can further be used in the creation of a cast resin or metal. The researchers investigated the most used materials for creating realistic busts. The pros and cons of the materials as well as their techniques were rigorously analyzed in comparison with the aluminium forming and welding technique. Welders are constrained as far as what they can create. Mostly welders produce iron gates, burglar-proof and security locks. There is the need to diversify the technique to be able to produce portraits as a step in experimenting and diversifying the material and technique. This study employed descriptive and studio-based research designs under the qualitative approach. Thus, an experimentation of the metal welding sculptural technique using the portrait of Ghana's first president and freedom activist Osagyefo Dr. Kwame Nkrumah was undertaken. This portrait was made entirely in aluminium using the Aluminium welding technique. The metal figure was formed with embossing, forming, chasing and repousse metal techniques. Based on the successful execution of this project, it has been established that aluminium welding technique can be used in producing a photorealistic representation of a figure aside the usual refractory materials such as clay and cement practiced by artists in Ghana.

Keywords: portrait; photorealistic; repousse; kwame nkrumah; aluminium.

\section{InTRODUCTION}

$(1)$ culpture is considered as the most customary and the most innovatory of the visual expressions (Konopka, 2003). It is a creative structure in which either hard or plastic materials are processed into threedimensional art objects (Rogers, 2016). The designs of sculptural figures might be displayed in unattached objects, in reliefs on surfaces, or in situations running from tableaux to settings that wrap the onlooker. An

Author a: Lecturer, Department of Industrial Art, Faculty of Art, College of Art and Built Environment, Kwame Nkrumah University of Science and Technology, Kumasi, Ghana. e-mail: ikegyei.gmail.com

Author o: MFA Student, Department of Industrial Art, Faculty of Art, College of Art and Built Environment, Kwame Nkrumah University of Science and Technology, Kumasi, Ghana.

Author p: Lecturer, Department of Educational Innovations in Science and Technology, Kwame Nkrumah University of Science and Technology, Kumasi, Ghana. e-mail: dickson.adom@knust.edu.gh awesome assortment of media might be utilized, including wood, dirt, elastic, stone, fabric, glass, metal, mortar, wax, and at times irregular "discovered" items. These materials might be sewn, cut, gathered, demonstrated, welded, cast, fashioned, formed, or generally moulded and consolidated. Jakab (2006) attests that clay is a kind of mud that can be manipulated when in the wet state. Clay is composed from the smallest grains of mineral from worn rocks. The crystals in clay gives them the ability to be able to hold water. Plastic clay is said to be very moist, which means it can be easily worked with. When subjected to high temperatures, it tends to become hard and impermeable. The main types of useful clays are formed from the mineral Aluminium silicate and is called kaolinites. Terracotta, adobe, and china clay are many different types of kaolinite clay used by artists in sculpting. Clay varies from white, grey, red, yellow, blue, or black depending on the composition of minerals in it. Each type of clay is attributed to different characteristics.

Spilsbury and Spilsbury (2008) characterize a representation bust as "a sculpted similarity in which the head and upper part of the body are detached". While "resemblance" can allude to different understandings, the reducing of the lower body, its sudden extraction, is the most essential element of the portrait bust. They further elaborated on the representation bust as a sculptural configuration by delineating in wide terms its move since Roman times. The possibility of portrait bust hast its roots from a solid relationship with the possibility of individual subjectivity and Neo-Classical sentimentality. The idea of portrait bust spins around what Malcolm Baker alludes to as the "classicising" bust, which fundamentally depicts the bust as a complex component got from Classical model. Welding on the other hand is the process of joining two or more metal parts, utilizing heat or pressure, or both. Welding on the other hand is the process of joining two or more parts also utilizing heat or pressure or both. Unlike forging, welding is a relatively recent metalworking technique introduced approximately between 1836 to 1881(Reed, 2018). It has ever since been known in association with Modern metal fabrication. Utilizing a propane light and some Aluminium brazing poles is a brisk approach to holding Aluminium without utilizing a welder. It makes for an exceptionally solid bond and with a little practice should be possible rapidly with incredible looking 
results. The blue Bernzomatic will work fine and dandy however, many welders incline toward utilizing the yellow premium touch as it's more sweltering and works much speedier (Woodworker, 2016). Osagyefo Dr. Kwame Nkrumah created more than 20 books and productions. He was a lead power on the Political hypothesis and Practical Pan-Africanism. Dr. Kwame Nkrumah benevolently committed his life to showing how future children and girls of Africa ought to set themselves up and endeavour to bring together Africa and bridle its riches for the advantage of all relatives of the mainland (Williams, 2016). Therefore, the aim of the project was to produce a portraiture sculpture of Osagyefo Dr. Kwame Nkrumah as a historic remembrance of him and his contributions to the wellbeing of Ghana by experimenting with the use of aluminium metal welding techniques.

\section{il. Materials and Methods}

\section{a) Materia/s}

The tools which were used in executing the work were as follows: chasing hammer, chasing tools, doming tools, clay modelling tools, rubber mallet, metal scriber, metal ruler, shears, tweezers, stakes and anvil, files (small and big as well as smooth and rough), adjustable saw frame and blades, welding rods, bee wax, planishing tools, tear drop tool, wooden mallet, pencil and Aluminium rods. Equipment used for the project included bench anvil, guillotine, gas cylinder, metal work bench, and the arc welding machine. The whole figure was formed in Aluminium.

\section{b) Research Methodology}

Shuttleworth (2016), Creswell and Poth (2017), Almalki (2018) and Cheek (2008) explain that qualitative research clarifies subjective exploration as a magnificent method for settling results and demonstrating or invalidating a theory. The structure has not changed for a considerable length of time, so is standard crosswise over numerous exploratory fields and teachings. After factual investigation of the outcomes, a far-reaching answer is obtained, and the outcomes can be talked about and published. Subjective trials likewise sift through outside components, if appropriately outlined, thus the outcomes picked up can be seen as genuine and fair. Subjective analyses are helpful for testing the outcomes picked up by a progression of subjective trials, prompting a last reply, and a narrowing down of conceivable bearings for subsequent research to take. The Qualitative research approach was, however, necessary in the study. Under the qualitative research design, studio-based and descriptive research methods were employed. The descriptive research method was used extensively to document the information and procedures of the study whereas the studio-based has to do with the fabrication of the artwork. Matua and Van Der Wal (2015) stated that descriptive research functions through a realistic presentation and point explanation of some people, events or artworks. Readers have the opportunities to be provided with a meticulous, systematic and vivid strategy of ensuring that the sentiments, ideas through which the artwork was carried out whiles the images work in the reader's mind (Sneck et al., 2016).

Curtis et al. (2016) opine that a descriptive research often tells readers the likely art they would see, or even what they would feel, hear, smell or even think. Because of this, powerful and strong adjectives were used in this study since they portrayed the researchers' ability to create pictures in their readers' minds. In a study by Hammersley (2016), it was identified that, many studies deal with artificial or natural methods like the technique adopted, their structure and changes over a period, their form or even their activity. This work therefore called for the application of man-made instruments and technique to create imagery in metal trough chasing and repoussé techniques. There was also analyses and description of objects or materials used in carrying out the research. Descriptive research was adopted because of the quest to provide a finished detail of the process and strategies adopted during experimentation and fabrication.

Candy et al. (2019) asserted that a studiobased research methodology is used to advance knowledge through practice. Such a research is identified as an original investigation carried out to attain understanding and knowledge in a particular area. Studio-based research thus employs idea invention, performance, artefact and image invention with design inclusive which translates into a substantial or newly enhanced insights in the practice (Orr, 2016). Candy et al. (2019) attest that an entire understanding of a study can be arrived at with reference to the work of art. The current study thus was carried out at the Metal Products Design Studio of the Department of industrial art, College of Art and Built Environment, Kwame Nkrumah University of Science and Technology to be precise.

\section{c) Design}

The artwork is a portrait of Osagyefo Dr. Kwame Nkrumah. Images of him were retrieved from an internet to get a vivid account of his likeness in other to transfer this likeness unto the artwork. 


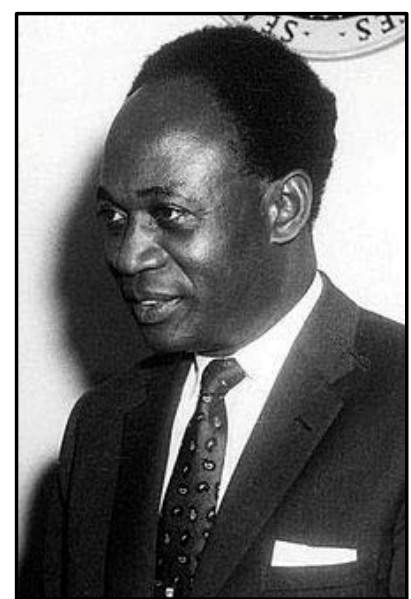

Fig. 1: Osagyefo Dr. Kwame

Nkrumah in a formal attire

Fig. 1 displays Osagyefo Dr. Kwame Nkrumah in a formal attire whereas Fig. 2 displays him in a traditional attire. Therefore, Fig. 2 was chosen not only because of the traditional attire which conveys the cultural heritage of the country but bears an utmost resemblance of the personality.

\section{d) Working Process}

This section entailed a vivid account of the production and finishing process of the Osagyefo Dr. Kwame Nkrumah metal portrait. The fabrication process has been categorized into the following areas:

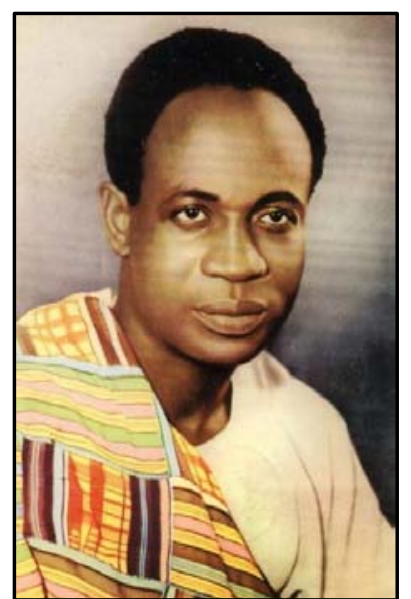

Fig. 2: Osagyefo Dr. Kwame Nkrumah in a traditional attire

- Metal forming

- Welding the parts together

- Fabricating the pedestal

To get a detailed model for the metal fabrication process, the portrait had to be modelled in clay. Clay was collected from the Ceramic Section, KNUST, and further processed by pounding and sieving in other to get an accurate consistency prior to the modelling process. A sizable amount was collected on a flat wooden board and a pestle was used to do the pounding.

- Clay modelling

- Mould making

e) Clay Modelling

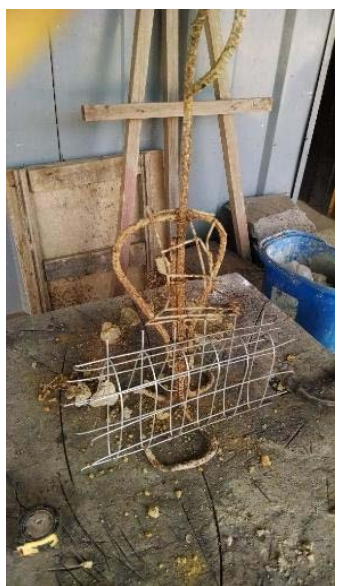

Fig. 3: Welded armature

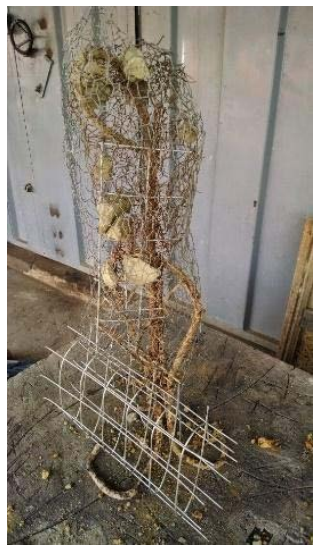

Fig. 4: Armature with mesh

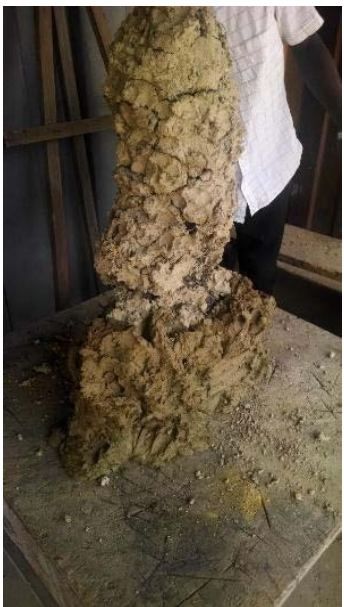

Fig. 5: Adding clay to armature 


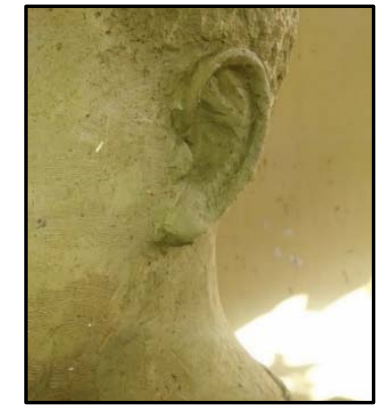

Fig. 6: Designing the Basic Bust shape

Pictures of Osagyefo Dr. Kwame Nkrumah (Figures 1 and 2) were used as a guide to develop the portrait first in clay. This was because a mould had to be done in cement in order to start the metal forming process. After acquiring an adequate amount of clay suitable for the proposed size of the clay model, an armature was first constructed (Fig. 3). The armature consisted of steel metal bars which were welded together. A metal mesh of varied sizes both big and small were wrapped strategically around the armature (Fig. 4) The armature was placed on the working table and the modelling process begun. The additive and method of clay modelling was employed on the modelling process. Clay was added bit by bit unto the armature to get the basic bust shape of Osagyefo Dr. Kwame Nkrumah which conformed to the reference pictures (Fig. 5). After obtaining the basic shape of the bust, the clay is left to harden to the leather hard state. The vital features of the bust were then modelled using the assorted clay modelling tools (Fig. 6). The head

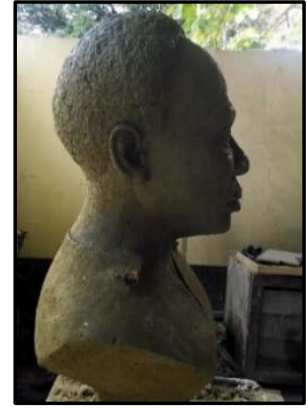

Fig. 7: The head shape

shape was first acquired followed by the facial characteristics. The facial characteristics of the bust was defined bit by bit to bring out the unique features of the portrait (Fig. 7) The unique features entail the special characteristics that will identify the model as Osagyefo Dr. Kwame Nkrumah.

The clay model surface is occasionally kept semi-wet in order to make necessary correction after critical analysis of the resemblance. A cloth was also used to cover the whole model in order to prevent it from getting bone dry. The model was then meticulously detailed with respect to the resemblance to the reference images. The textures on the head which represented the hair were created with short broom. The bottom of the short broom was used to create these textures by means of hitting the areas of the hair with the bottom of the broom. When the desired features were obtained (Fig. 7) the whole surface of the model excluding the textured parts were burnished with a hand shovel to get the surfaces very smooth.

\section{f) Mould Making}

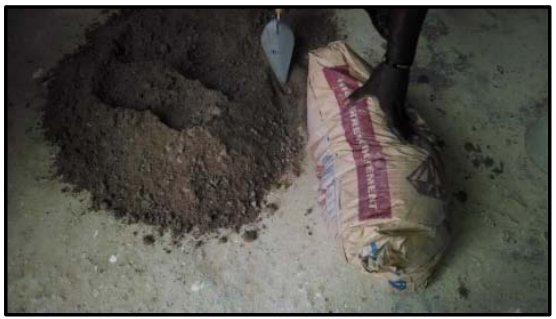

Fig. 8: Mould preparation

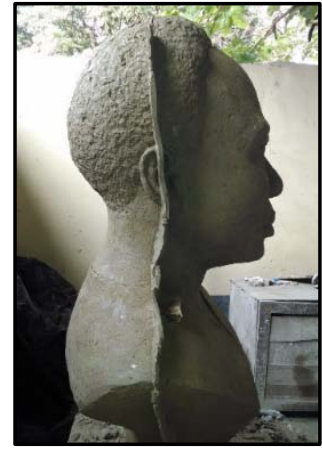

Fig. 9: Clay wall

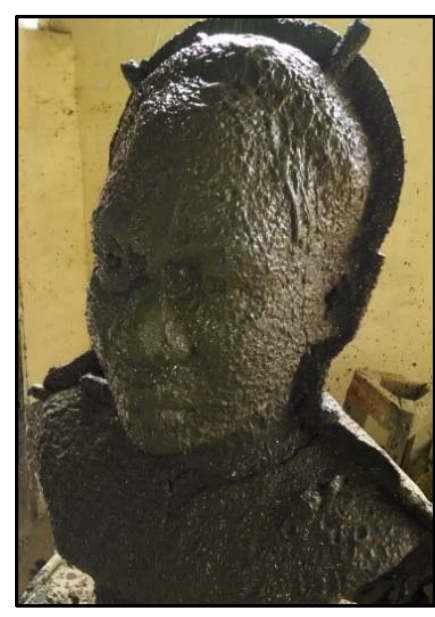

Fig. 10: Coat for mould A 


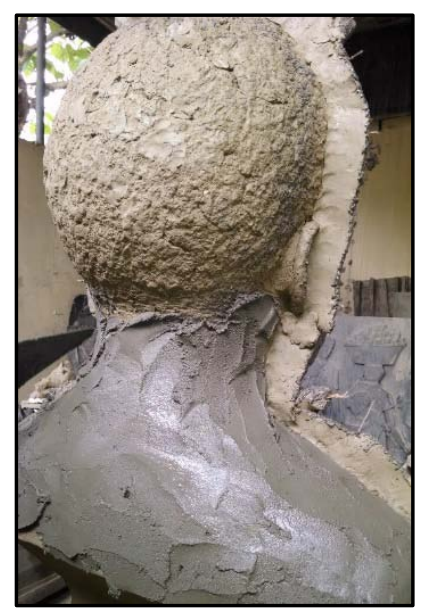

Fig. 11: Coat of mould B

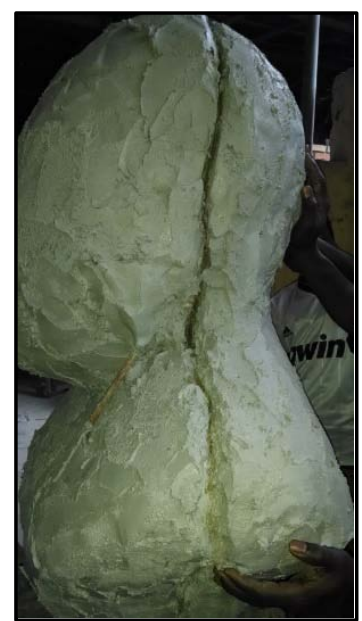

Fig. 12: Dried mould A and B
After having obtained the desired portrait model, the model was then prepared to cast a mould. The clay model was virtually divided into two parts namely mould ' $A$ ' and mould ' $B$ '. A line was drawn from the left to the right side of the model in order to create two-part mould which was categorically labelled ' $A$ ' and ' $B$ '. Mould ' $A$ ' is the front part of the model which entails the face, bit of the ears and the chest whereas mould ' $B$ ' covered the opposite part which was the remaining half (Figures 10 and 11). Clay wall (Fig. 9) was mounted following the parting line to serve as the parting wall for mould ' $A$ ' and ' $B$ '. The wall measured the proposed thickness or height of the mould.

The application of the mould material was done in two parts namely, the first and second coat. The material which was used for the mould was cement and chicken net to make the mould strong and unbreakable. The dry cement was poured on the concrete floor (Fig. 8) and mixed with water to get a desired consistency for the first coat. In order to accurately pick the details of the clay model, a more liquid mixture of cement and water was prepared and applied directly unto the clay model. The first part which is the front part, mould ' $A$ ', of the clay model was first covered in the first coat (Fig. 10). When every part of the front part of the clay model (Fig. 11) is covered in the mould material, it is left to dry.

The second coat mixture which is thicker and more solid as compared to the first coat was applied unto the first coat bit by bit by the additive method of mould application. The second coat mixture was repeated to get the desired thickness which is achieved by meeting the thickness of the clay wall to complete the first front mould (mould ' $A$ '). The back or the remaining part of the model which is separated by the clay wall was prepared next. The clay wall was removed before the first coat of the back (mould 'B') in order not to create a gab at the parting joint. Another parting joint was created using clay which was in a more liquid consistency as compared to the clay wall and applied to the edge of the dried cement parting line or wall of the first mound (mould 'A'). The first coat was then prepared and applied unto the back part of the clay model (mould 'B') to first take the back details just like the front mould. Chicken net was wrapped around the model after the first coat in order to strengthen the mould. The second coat was applied after the first coat had dried following the same procedure as the front mould to get the desired thickness. When the second mould (mould 'B') is complete, it was then left to dry in order to be separated (Fig. 12). After the two parts mould (A \& B) have completely dried, they were then separated and removed. Since the mould has not completely dried due to the size, it took a longer time for it to harden and the clay model was destroyed during the separation process.

A wooden stick was used to hit the parting joint to split the two halves in order to facilitate the parting process. Mould ' $A$ ' was removed first followed by mould 'B'. Traces of clay were left in both sides. The clay was removed by scooping them out bit by bit until a greater amount has been removed including the armature. After scooping all the clay out of the mould, the mould was washed under running water with a scrub brush to remove the small clay traces which were trapped in the intricate areas of the mould especially mould 'B' which has the face. Greater care in handling the moulds was paramount since they were heavy and any mistake will beak or destroy the mould.

\section{g) Metal Forming}

Having derived the two-part cement mould, the Aluminium sheets were used to pick the shape of the figure in the mould in separate parts. All parts of the bust were formed separately and later welded together to form a completely stable unit. The broader sections were formed first. The mould was apparently divided into sections. Since the mould is in two parts each part will be formed separately and joined together. 
h) Forming the flat portions

The flat area of the mould was traced with sugar paper (Fig.13). Due to the flexible nature of sugar paper, it was however appropriate for acquiring the shapes of the various parts in the mould excluding the intricate areas such as the nose, mouth, ears and eyes. Sugar paper was arranged in the mould to take the shape of the various sections (Fig. 14). The papers were then meticulously cut with a pair of scissors in accurate alignment to meet each other.

After tracing all areas of the mould excluding the intricate parts such as the nose, eyes, ears and mouth, the papers were taken out of the mould and placed on the Aluminium metal sheets to be traced and pierced or cut. Pencil was used to trace the shapes of the papers which assumed the shapes of the sections on the Aluminium sheet. In order not to create confusion, a naming structure was developed by the researchers for the mould. Every piece of sugar paper which represented a portion of the mould was named in numbers according to the specific mould it belonged. The sections of mould ' $A$ ' for example was named using the description of the portion of the mould. For example, in mould ' $\mathrm{B}$ ', the portion which represented the back of the bust was named 'back 1', 'back 2' as well as 'side back 1' and 'side back 2' which represented the side parts of the back.

i) Forming the reference models

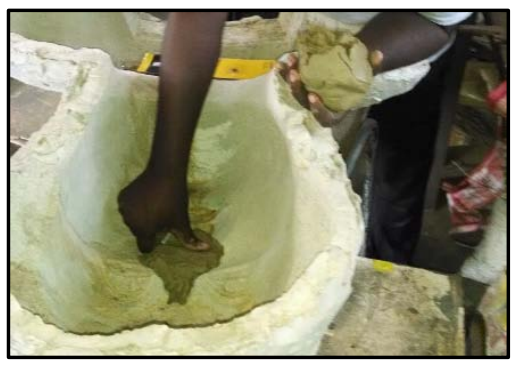

Fig. 15: Taking shape with clay

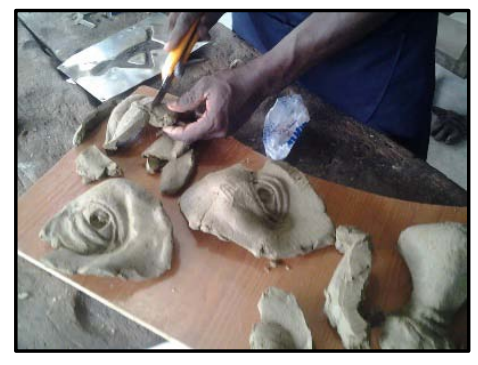

Fig. 16: Eyes, mouth \&nose

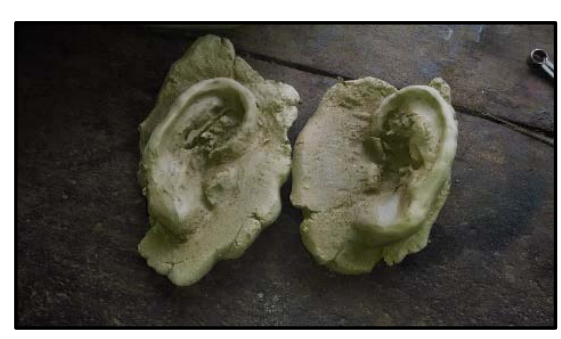

Fig. 17: Clay models of ears

Complex areas such as the nose, eye, ear, eyes and the mouth in mould ' $A$ ' was traced with a different approach. Instead of using the sugar paper which would have been impossible to obtain all necessary parts, those areas were picked up using clay (Fig. 15). Lumps of clay was prepared pushed into all these areas to get the exact shapes (Fig. 16). They were then removed and placed in a cool environment to dry (Fig. 16 \& 17). These clay parts represented the exact shaped in the mould which made chasing and repousse of these portion much easier since they served as references for the forming process. 


\section{j) Forming the broader sections}

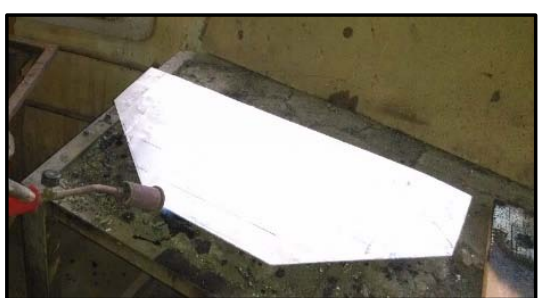

Fig.18: Annealing Al. sheet for the forming processes

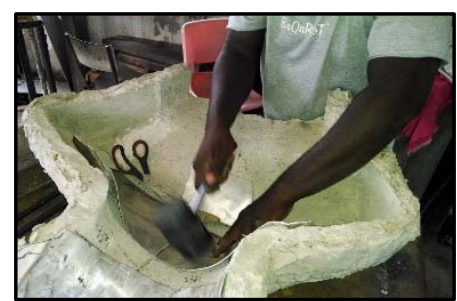

Fig. 19: hammering Al. sheet for the bottom part of ' $\mathrm{B}$ '

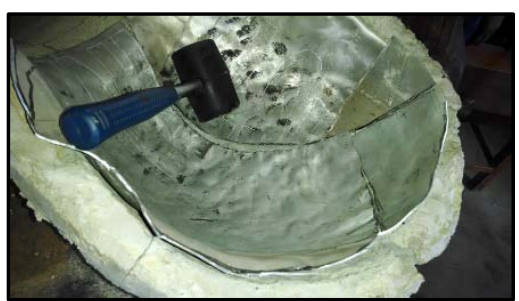

Fig. 20: hammering Al. sheet

for the upper head part
After tracing unto the Aluminium sheet, the traced shapes were pierced out using the jeweller's saw frame. When all the traced shapes have been pierced out, they were annealed (Fig. 18) to prepare them for forming and bending processes. The various sections were placed one after the other in the mould and a rubber mallet and a wooden stick was used to hit the metal to conform to the shape of the mould. The chest areas for example was arranged in sections and a rubber mallet was used to hammer (Fig. 19) them to shape. When the metal hardens, the annealing process was repeated and the process continued. All the pieces were hammered in the cement mould until they conformed to the shapes of the areas which they meant to be. Each section was carefully placed to touch each other at their edges. After hammering, the researchers realized that the metal pieces were overlapping instead of aligning at the edges. This was as a result of the malleable nature of the Aluminium. The metal somewhat expanded and distorted the initial shape in which it was cut. The shapes were resized due to the expansion and all excess parts were marked with pencil and pierced. They were then rearranged in the mould to check their alignment.

The parts which were not well aligned were removed and further filed to obtain the desired results.
The edges which were distorted due to the excessive annealing and tampering were placed in the mould and straightened to get flashing edges at every point. Several checks were conducted to make sure they aligned properly in the mould so as to obtain the same shape as the model if arranged and welded together. Every section of the sheets in the mould was named according to the same naming structure which were used for the sugar paper sections.

The same approach was used in defining the face of the bust. Aluminium sheets that were pierced for the forehead, cheeks, chin and the other facial features of the head were annealed and placed in the respective part of the mould and the rubber mallet was used to get the basic shape of the face. The face was divided into four parts, the forehead and two parts which includes half of the nose and mouth and the chin to half of the neck. The Aluminium sheets were arranged accordingly and hammered to get the sunken shapes partially. The wooden stick was used to get the sunken areas of the nose, eyes, ears and mouth. These areas were not hammered too deep since they would be cut off and replaced with the exact one after the chasing and repousse process.

k) Forming the eyes, nose, mouth and ears in metal

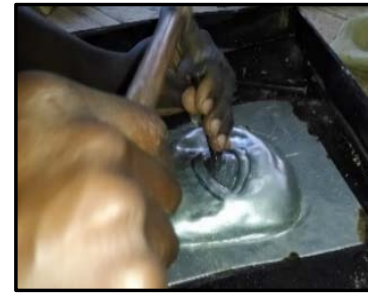

Fig. 21: Forming eyes

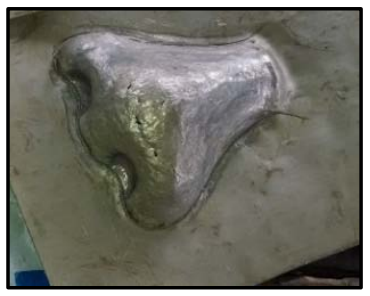

Fig. 22: Forming nose
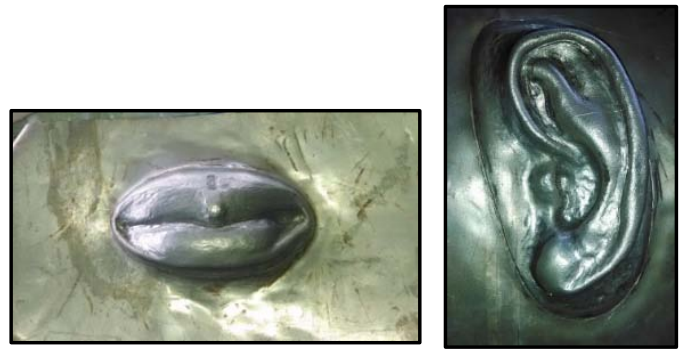

Fig. 23: Forming mouth Fig. 24: Forming ears

After creating the basic facial part of the mould, the intricate facial features were fabricated next using a different approach namely chasing and repousse. The clay models of the eyes, nose, mouth and ears served as reference models on which the researchers looked unto to form them separately one by one. 


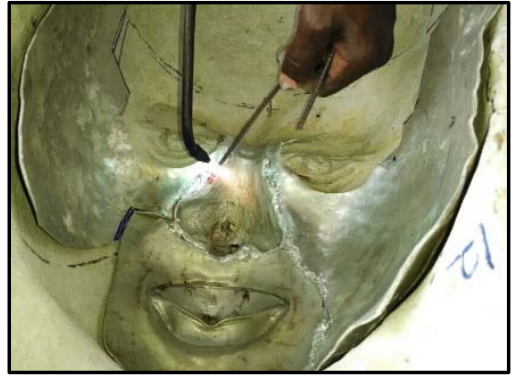

Fig. 25: Welding parts

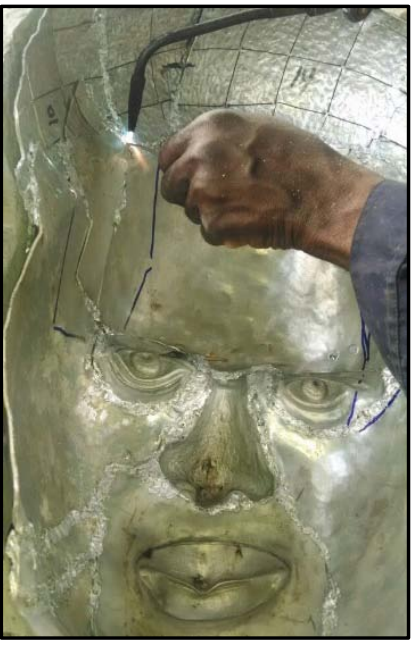

Fig. 26: Welding forehead

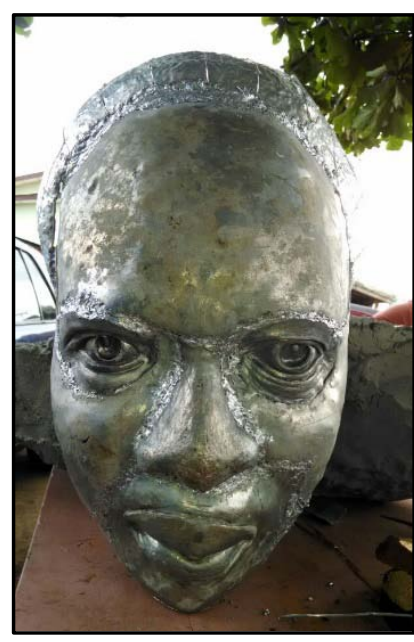

Fig. 27: Welded face parts

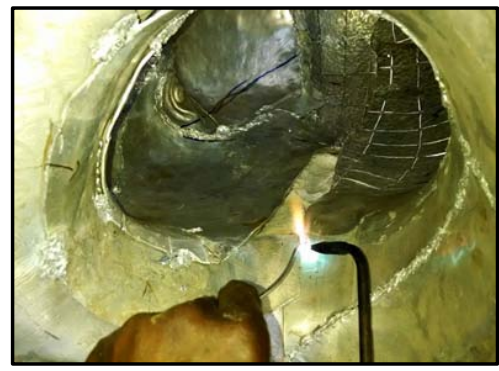

Fig. 28: Welding neck region

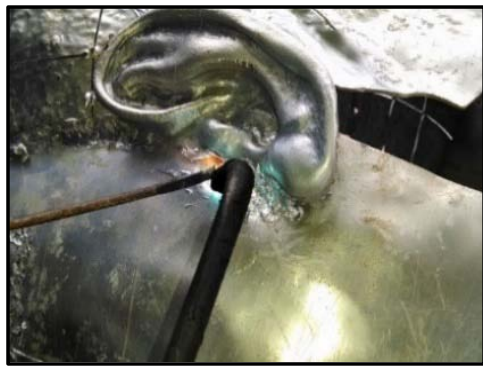

Fig. 29: Welding ears

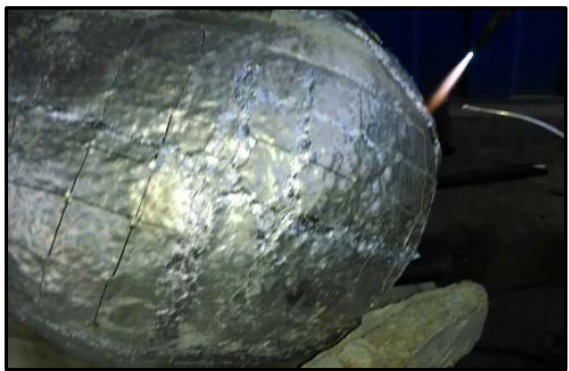

Fig. 30: Welding head
The metal pieces were welded bit by bit until the whole thing was completed. The face was assembled first. The chased facial elements being the eyes, nose, ears and lips were pierced out using the jewellers' saw frame after the chasing and repousse process was completed. These facial elements were fixed into the broad surfaces which completes the head. In order to properly execute the welding process of the face without distorting the desired figure the pieces of metals were placed in their respective portions in the mould ' $A$ ' (Fig.25) and the welding process begun from the bottom which is the jaw region to the forehead region. All the eyes, nose and lips excluding the ears were welded following the areas of their contact region (Fig 25).

In order to properly secure the welded joints, the welded parts which were welded in the mould were removed from the mould and turned over to re-weld all loose parts to reinforce the welded joints. When all edges have properly been secured, the welded parts were placed back into the mould to complete the figure of the face. The eyes were also placed together with the welded portion which were the nose the lips and the cheek. When the face in mould ' $A$ ' was completed, the metal pieces which forms the head was also placed in their respective portion and welded together. The grid line spaces in the hair was also welded to close them up
(Fig. 26). The process continued until all metal elements of mould 'A' had been well welded (Fig. 27).

When the mould ' $A$ ' metal figure is completed, the same procedure is followed to achieve the desired outcome. Unlike the metal figure for mould 'A', mould 'B' has no intricate detail designs such as the eye, nose and ears so the metal parts were placed in their respective portions in the mould to be welded together. The metals from mould ' $\mathrm{B}$ ' were assembled from the bottom to top. The lower region of the mould which is the back of the figure was welded first which consisted of three metal pieces. After welding these parts, the next was welding to join the rear region. Unlike mould ' $A$ ' metal figure, the mould ' $B$ ' metal figure had to be welded on the edge of the mould ' $A$ ' figure instead of the complete mould ' $B$ ' metal figure which would make joining the complete parts of ' $A$ ' and ' $B$ ' more difficult. The part of the neck on mould ' $B$ ' consisted of three metal pieces. The welded part of the neck was welded to the back of the figure and joined to the edge of the mould 'A' figure (Fig. 28). The welded joints were further secured by closing all gabs. The back of the head in mould 'B' however consisted of five parts excluding the grid-pierced pattern of the hair region. These parts were welded to join the whole welded figure directly until it was complete. When the welding process of the pieces of mould ' $A$ ' and ' $B$ ' were completed, there happened to 
be holes or spaces in the figure. This included the area where the ears will be fixed. The metal parts with the chasing of the pair of ears where placed on their respective positions at edges of the sides of the joined metal figure of mould 'A' and 'B' and welded (Fig. 29).
Sugar paper was used to trace the remaining areas with the aid of a pencil by placing the piece of sugar paper at the back of the affected area and the pencil was used to draw the shape of the hole along the edge. Fig. 30 shows the welded back of the head ' $\mathrm{B}$ '.

m) Producing the Pedestal

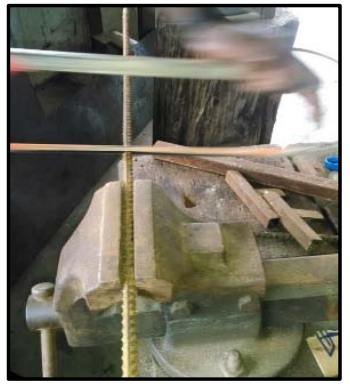

Fig. 31: Cutting rods

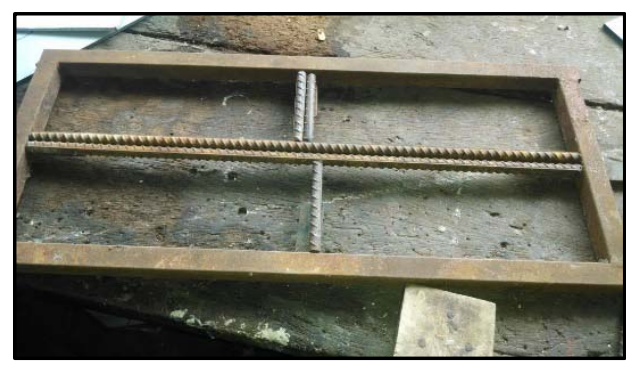

Fig. 32: Pedestal base

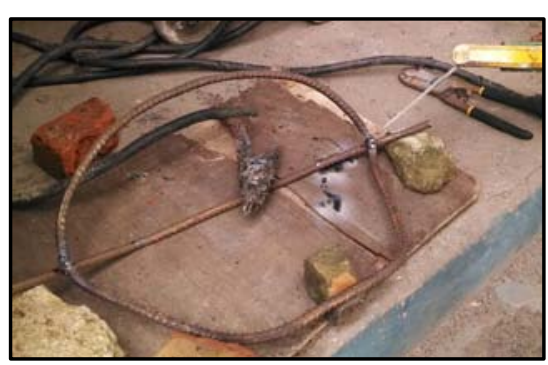

Fig. 33: Inner part of pedestal
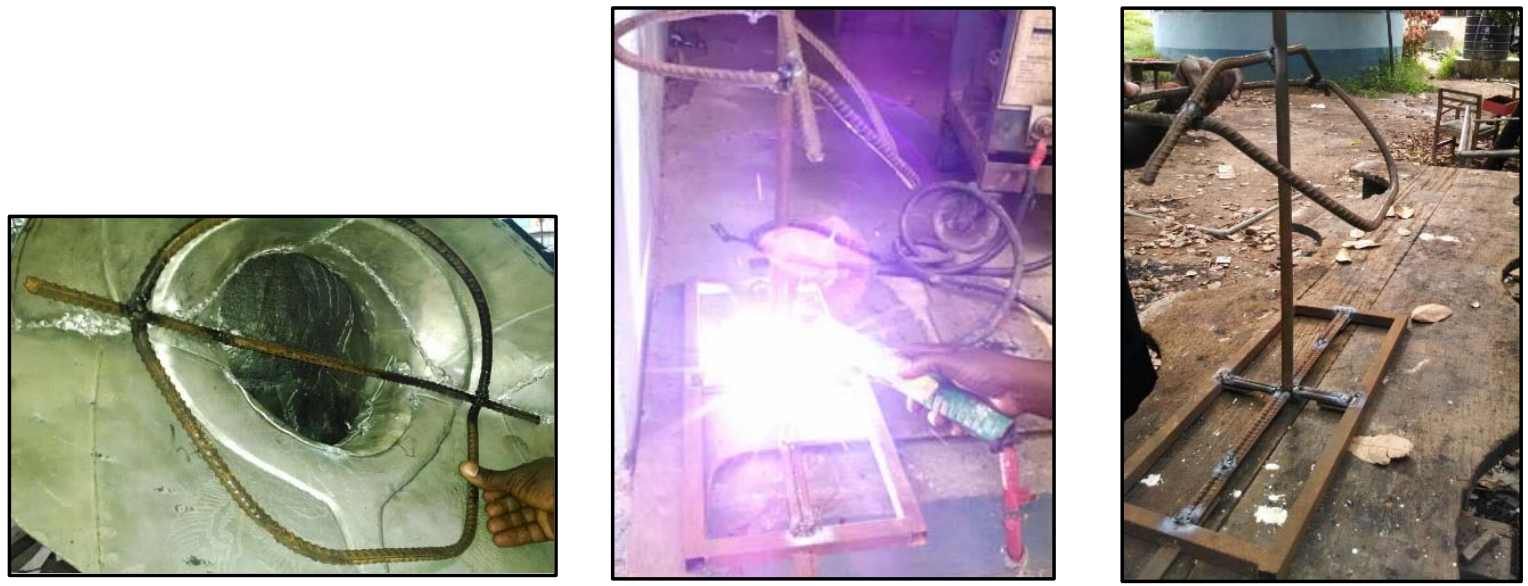

Fig. 34: Inner support

Fig. 35: welding inner to base support

Fig. 36: Complete pedestal

A pedestal was fabricated on which the metal figure will rest on. The pedestal is made up of iron rods and steel pipes. The iron rods and steel pipes were cut to a desired size (Fig.31). The base of the pedestal was constructed using these square pipes and iron rods. The square steel pipes were welded together to form a rectangular shape. The middle of the rectangular shape was filled with a cross of double round iron rods. A single metal rod was bent on an anvil to conform to the curvature of the inner base wall of the metal portrait figure. A single rod was welded in the middle of the curved iron rod in an overlapping manner (Fig. 32 \& 33). In order to connect this curved iron rod and the rectangular metal base, a single iron rod was cut and welded to join the two (Fig, 34). The intersection of the iron rods in the middle of the rectangle was where the iron rod was welded. The rough welded joints were grinded using the hand grinder machine.

\section{ili. Results and Discussion}

\section{a) Results}

The results of this study is displayed as in Fig. 37. There was no discovery during the review of related

literature that amalgamated the chasing and repousse technique with the Aluminium welding or any type of metal welding. Most of the works that were produced were either one of them. A typical example is the artist Jordi Diez Fernandez who produces figurative sculpture with scrap metal. The art of photorealism is not only limited to only refractory materials or the metal casting techniques but metal sheet forming and the welding technique can be combined to produce a portrait figure in metal other than casting as the study has proven.

The main aim of the study was to fabricate Osagyefo Dr. Kwame Nkrumah using the welding technique. The study revealed an infallible truth that, provided there is an outmost resemblance in the clay model of the proposed figure, it is possible to transfer that resemblance unto the metal. Following the mould of the clay model and the reference images as well, made the final metal figure less ineffective. Therefore, the resemblance of the clay model was paramount to the successful execution of the metal portrait of Osagyefo Dr. Kwame Nkrumah. Another aim of the project was to experiment and explore the Aluminium welding technique into forming the realistic portraiture. The 
Aluminium welding technique was experimented with pieces of Aluminium sheets. Continues practice of this technique alleviates the difficulty of this technique since Aluminium is a very light metal and if critical care is not taken in the welding process, the design might be distorted. Finally, the study was also aimed at assessing other portrait-making techniques such as modelling and casting in comparison to welding. Clay and other refractory materials in modelling as well as casting are the major mediums through which artists express their three dimensional portrait making. The clay modelling technique was however explored and the researchers discovered that it is easier to produce a portrait figure in clay having the needed skillset unlike the metal which is also malleable but cannot be altered after rigorous subjection to hammering and annealing.

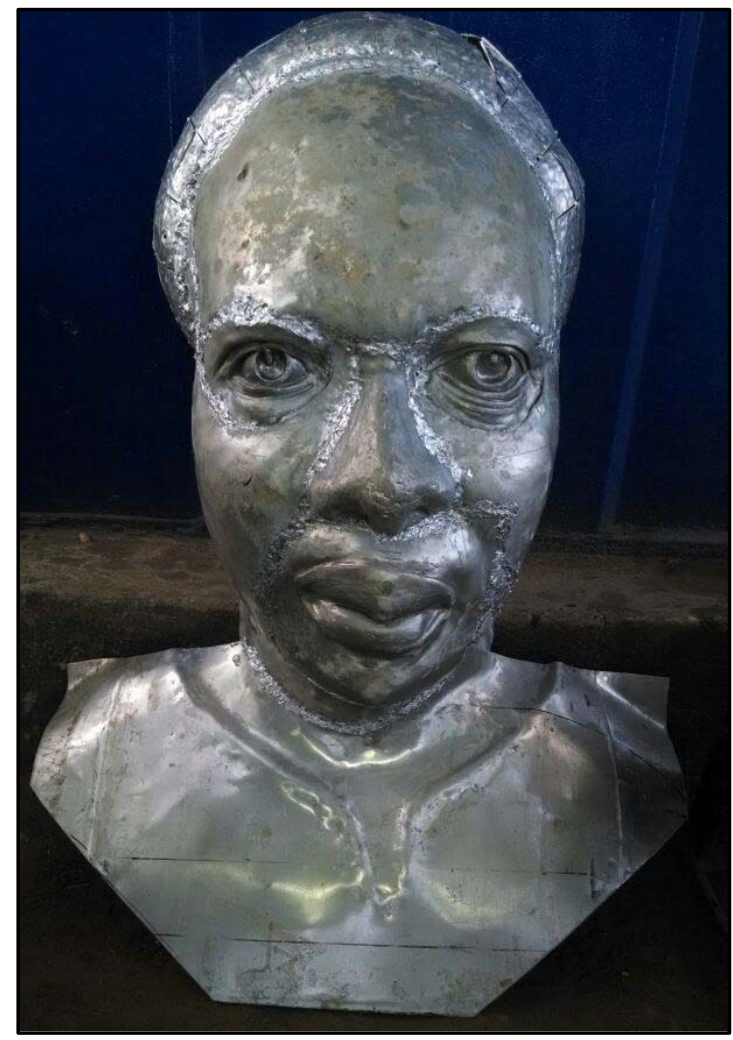

Fig. 37: The final metal bust of Osagyefo Dr. Kwame Nkrumah

\section{b) Appreciation}

Osagyefo Dr. Kwame Nkrumah was the main centre of focus in this project since he was the first leader of Independent Ghana and even before the time former Ghana which was known as the Gold Coast. On March 6, 1957, at 12 am, Nkrumah declared Ghana to be an independent nation. In celebration and in respect he was given the title of Osagyefo by the people, which translates as "redeemer" or "the victorious one" in the Akan tongue. Today, Nkrumah is still one of the most respected leaders in African history. His legacy lives on today in the continued existence of Convention People's Party. He has been honoured throughout the nation. A typical example is the Kwame Nkrumah Mausoleum and the Kwame Nkrumah University of Science and Technology.

The facial characteristics of the metal figure is what defines it as a portrait of Osagyefo Dr. Kwame Nkrumah. These characteristics includes the eyes, ears, nose and the overall structure of the face. These characteristics are not dissimilar from that of the clay model which was imprinted in the mould. The whole metal figure was successfully executed based on the dependency on the elements and principles of design. Without these principles and elements, the metal figure would not have resembled the clay model. The outfit of the figure which is the jumper represents the uniqueness and diversity of the African culture. The African jumper that complements the kente and other types of cloths and fabrics are worn by Ghanaians. The chasing and repousse technique employed in fabricating the vital features of the head was very essential in the success of the project. Without these techniques, there wouldn't have been a more detailed representation of the eyes, nose, lips and eyes in the sheet medium. Chasing helped entirely in building a replica of the vital features based on the clay reference models. The repousse technique also brought out the sunken and raised details of the vital features in the effort of creating a replica.

The Aluminium welding technique was also suitable given the thickness of the Aluminium sheets 
and was able to fuse beautifully in a clean line. All assembled sections of the metals originating from the mould ' $A$ ' and ' $B$ ' were successfully fused together using the Aluminium welding technique. Shapes formed using the chasing and repousse technique as well as those formed using the embossing and hammering techniques were all harmoniously combined into the single unit through the Aluminium welding technique. The Aluminium metal was suitable for this project. Aluminium is a light metal and can be manipulated into different shapes.

\section{Conclusion}

The successful execution of this project has revealed that portraits are not limited to clay and other refractory materials and also metal cast, but there can be an amalgamation of the chasing and repousse technique as well as embossing and the Aluminium welding technique. The research has proven that a metal sculpture can be produced without the casting technique which is usually less accurate given the size and the results can hardly be controlled based on the works that are produced in Ghana. The clay however is a suitable material due to its malleable nature. It can be altered continuously until the desired shape is acquired. Clay can be added or subtracted to get the desired form. The clay however has to be cast or fired in order to make it more durable but the whole process consumes a lot of time and money before the final work is done. Aluminium is a metal that doesn't tarnish, corrode or rust. It can maintain its appearance and lustre for a long period of time. The study has also introduced a new approach into portraiture. This will add to the existing knowledge in the making of photorealistic portraiture. The project would give room for metal artists to explore their creative prowess in this field of study.

Based on the successful execution of the project, it has established the fact that the Aluminium welding technique can be used in producing a photorealistic representation of a figure aside the usual refractory materials such as clay and cement practice by local artist. Having achieved a realistic portrait figure of Osagyefo Dr. Kwame Nkrumah, the researchers can boldly recommend this process as an alternative for metal artists in this field and other fields alike. Moreover, the researchers would like to recommend that metal artists should experiment with different techniques other than the usual which are mostly clay modelling, cement modelling, cement casting, metal casting etc. Metal artists in Ghana should explore other methods of making portraits in other to pave way for diverse techniques and materials which will be much better and less expensive and also achievable if not better, the same results as the old methods of photorealistic portraiture. Aluminium is a less expensive metal and malleable. It does not corrode and therefore it is the best metal for making photorealistic portraits. The researchers will therefore recommend Aluminium as the right metal for making busts and other related artefacts.

\section{References Références Referencias}

1. Almalki, S. (2016). Integrating Quantitative and Qualitative Data in Mixed Methods Research-Challenges and Benefits. Journal of Education and Learning, 88-296.

2. Candy, S., Scupelli, P., \& Brooks, J. (2019). Teaching Futures: Trade-offs Between Flipped Classroom and Design Studio Course Pedagogies. Design Revolutions.

3. Cheek, J. (2008). 'Research Design' in LM Given (Ed) The Sage Encyclopedia of Qualitative Research Methods Vol 2 London: Sage, p 761-3.

4. Creswell, J., \& Poth, C. (2017). Qualitative inquiry and research design: Choosing among five approaches. Sage publications.

5. Curtis, E., Comiskey, C., \& Dempsey, O. (2016). Importance and use of correlational research. Nurse researchers, 23(6).

6. Hammersley, M. (2016). Reading ethnographic research. Routledge.

7. Jakab, C. (2006). Clay. North Mankato, Minn.: Smart Apple Media.

8. Konopka, D. (2016). sculpture. Csmt.uchicago.edu. Retrieved 28 January 2016, from http://csmt. uchicago.edu/glossary2004/sculpture.htm

9. Matua, G., \& Van Der Wal, D. (2015). Differentiating between descriptive and interpretive phenomenological research approaches. Nurse researchers, 22(6).

10. Orr, K. (2016). The Live Project and Prototyping as a Paradigm for Linking Teaching and Research in the Architectural Design Studio. Brookes e-Journal of Learning and Teaching, 8(1-2), 1-21.

11. Reed, B. (2018, March 20). The History of Welding. Retrieved from Fairlawn Tool, Inc.: https://www. fairlawntool.com/blog/history-of-welding

12. Rogers, L. (2016). Leonard R. Rogers. Encyclopedia Britannica. Retrieved 28 February 2016, from http://www.britannica.com/contributor/Leonard-RRogers/2505

13. Sneck, S., Saarnio, R., Isola, A., \& Boigu, R. (2016). Medication competency of nurses according to theoretical and drug calculation online exams: A descriptive correlational study. Nurse education today, 36, 195-201.

14. Shuttle worth, M. (2016). Definition of Research How is Research Defined?. Explorable.com. Retrieved 10 January 2016, from https://explorable. com/definition-of-research

15. William, P. (2016). Osagyefo Dr. Kwame Nkrumah, Ex-Head of State: 1957 - 1966. Ghanaweb.com. 
Retrieved 4 June 2016, from http://www.ghanaweb. com/GhanaHomePage/people/person.php?ID =177

16. Woodworker, D. (2016). How to Weld Aluminium without a welder. Instructables. Retrieved 20 March 2016, from http://http://www.instructables.com/id/ How-to-Weld-Aluminium-Without-a-Welder 